\title{
Gastrointestinal Stromal Tumor pT1 TNM
} Finding $\mathrm{v} 7$

National Cancer Institute

\section{Source}

National Cancer Institute. Gastrointestinal Stromal Tumor pT1 TNM Finding v7. NCI

Thesaurus. Code C90048.

Gastrointestinal stromal tumor with tumor size $2 \mathrm{~cm}$ or less in greatest dimension. (from AJCC 7th Ed.) 